\title{
La construcción legendaria de la identidad. De los estereotipos sobre Castilla a la conmemoración de Villalar*
}

\section{CASTILla Y LA INVENCIÓN DEL CARÁCTER NACIONAL}

\section{Carácter y estereotipos nacionales}

La historia oficial del folklore en cuanto a presunta ciencia que estudia una presunta Cultura Popular, ha estado enormemente condicionada en los países europeos por el fervor nacionalista y ello, a menudo, en tales grados que muchos estudios folklóricos estuvieron y, en realidad, aún lo están, dirigidos a la propaganda política en favor de esta o aquella unidad nacional ${ }^{1}$. Paradójicamente, y como ha señalado Peter Burke, las poblaciones campesinas con cuyo folklore solian identificarse los afanes nacionalistas se encontraban, por lo general, un tanto ajenas a estos "tejemanejes" de la política. Los nacionalismos fueron y son, en muchos sentidos, más cosa de élites intelectuales y políticas que de pueblos ${ }^{2}$.

Antropólogos catalanes como Joan Prat han señalado esa progresiva configuración de unos símbolos de identidad nacional a partir de una tradición que podríamos llamar "inventada". En el caso catalán, parece claro que reducir la rica identidad de toda una cultura a los signos más visibles de la bandera, la sardana y las diferencias lingüísticas puede resultar empobrecedor ${ }^{3}$. Como lo es para la identidad castellana reducirlo todo a

* La parte central de este trabajo fue realizada dentro del proyecto "Antropología urbana en contexto financiado por la Comisión Internacional de Ciencia y Tecnología (CICYT), n. ${ }^{\circ}$ PBS 89-0200.

1 Claude KARNOOUH, "On the use if Folklore or the avatars of Folklorism", Communication \& Cognition, vol. 17, n." 2/3 (1984), pp. 315-335.

2 Peter Blrke, Popular Culture in Early Modern Europe (New York: Harper Torchbook, 1978), pp. 12-13.

3 Sobre el papel jugado por el folklore y los folklorismos en la evolución de la cultura catalana véase, entre otros muchos trabajos, el de Llorenç PraTs, "Sobre el carácter conservador de la cultura popular" en La cultura popular a debat. coordinado por Dolors LloparT, Joan PRAT y Llorenç PRATS (Barcelona: Fundació Serveis de Cultura Popular / Edit. Alta Fulla, 1985), pp. 72-80. 
la dulzaina y a la jota. Hoy en día, al fondo de utilizaciones más bien forzadas de lo folklórico y, también, de un interés admisible por conocer los rasgos culturales que podrían caracterizar a cada comunidad, no resulta difícil descubrir cierta creencia - a veces vaga, otras más furibundamente declarada - en algo así como un carácter nacional. Nosotros (los catalanes, los vascos, los castellanos...) somos - y siempre hemos sido- de esta manera, y los otros (gallegos, aragoneses, andaluces, etc.) de esta otra.

La discusión sobre el carácter nacional a poco puede llevarnos, fuera de -como decía Caro Baroja- amenizar los viajes en tren y las horas aburridas en los comedores de hotel. Sin embargo, el propio Caro Baroja escribió una obra, si bien desmitificadora, sobre este tema, manifestando en ella cierta preocupación por el interés que los antropólogos venían demostrando en torno a un asunto que, en sus derivaciones políticas y genocidas, ya había hecho bastante daño en Europa ${ }^{4}$. La bibliografía sobre esta temática del carácter nacional se fue incrementando durante algún tiempo en países como los Estados Unidos, aunque conviene puntualizar que siempre tratando de estereotipos de identidad más que de caracteres nacionales.

¿Cuál es la diferencia entre carácter y estereotipo nacional? El estereotipo nacional, en gran parte basado en el folklore pero también en la manipulación de la Historia, es lo que unas gentes piensan de ellas mismas y de los otros; mientras que el carácter nacional, si es que existe, haría referencia a lo que esas gentes verdaderamente son. Hablar del carácter nacional de los unos y los otros es, como dice Caro Baroja, poco más que una actividad mítica, pues el que habla siempre se ajusta a una tradición elaborada en mayor o menor grado, hecha de estereotipos - que es como decir de ignorancia de los otros-y de prejuicios 5 . Se ajusta, digamos, a un modelo que le viene dado y que no es verdad ni mentira, ya que puede tener de las dos cosas, o ser enteramente falso.

Independientemente de la verdad - siempre tan relativa- que esos juicios contengan, lo que importa es si la gente cree en ellos. Y cree. Por lo tanto, el carácter nacional es sobre todo elucubración, siempre condicionada por la tradición - culta y popular-y determinados intereses políticos que cambian según el momento histórico. Si en realidad existe un carácter nacional, difícilmente podríamos llegar -condicionados como estamos- a conocerlo. Sin embargo, los estereotipos existen -verdaderos o falsos- y las gentes se conducen de acuerdo con ellos, por lo que son totalmente estudiables.

+ Julio CARO BAROJA, El mito del carácter nacional. Meditaciones a contrapelo (Madrid: Seminarios y Ediciones, S.A., 1970). p. 71.

= Ibid. pp. 71-72. 
Tanto si hablamos de carácter nacional como de estereotipos, habremos de tener en cuenta una serie de limitaciones o condicionamientos respecto a ellos y su posible validez como objeto de estudio, que los más sagaces tratadistas del tema ya han apuntado en sus obras: así, el cambio y sucesivas alteraciones de lo que hoy conocemos como "naciones". Las líneas político-administrativas que separan países -y, en el caso que tratamos de los pueblos de España, regiones y provincias- han evolucionado al paso del tiempo, y, como sabemos, no se corresponden en muchísimos ejemplos con las que podríamos considerar auténticas áreas etnográficas y culturales.

Hablando de Castilla, ¿de qué Castilla hablamos?: ¿de la de la Edad Media, de la de los siglos XVI y XVII o de la Castilla y León actuales? Hay otros aspectos que, por así decirlo, "estratifican" - desde dentro- la pretendida unidad del carácter y del estereotipo: diferencias de clase, de oficio, de edad y de sexo. Algunos viajeros destacaron ya, desde el siglo XIX, como podrían encontrarse más coincidencias entre los pastores o campesinos de distintos países que entre personas de distinta posición económica y diferente cultura dentro de la misma nación.

Los mismos estereotipos no son en absoluto estáticos; y, así, el español que era visto en la Europa del siglo XVI como paradigma del buen diplomático por su cortesía, gallardía y justeza, pasa a convertirse en un estereotipo de fanático religioso o en el vacío figurín romántico de exotismo y torería, tan difundidos aún en la actualidad. Los estereotipos tienen como base un modelo ideal que resume todo un sistema de valores. Todo juicio de imagen sobre los otros y sobre nosotros mismos precisa ese modelo - positivo o negativo- como punto de comparación. Reflejan, pues, los estereotipos -y los chistes étnicos derivados de ellos- modelos culturales de quienes los crean, proyectándose, a menudo, todo lo que es considerado como abominable sobre otro grupo o etnia.

Decía el escritor Anthony Burgess ${ }^{6}$, en un interesante artículo sobre el carácter británico, que es más fácil definir a un británico en términos de lo que no es -en su opinión, un francés- que mediante atributos positivos, de los que no está muy dispuesto a alardear el británico en general. Stanley Brandes aplica este principio de proyección e intenta demostrar, en su libro Metaphors of Masculinity, cómo los andaluces del pueblo que él estudia - los cuales se autodenominan curiosamente como castellanos - proyectan sobre los gitanos del lugar los defectos que saben que otros grupos - castellanos precisamente - les atribuyen a ellos: ser

6 Anthony Burgess, "El carácter británico" en El País, 26 de abril de 1987. 
despreocupados, machistas, perezosos, exagerados, no fiables, charlatanes, etcétera ${ }^{-}$.

\section{Los estereotipos en torno a Castilla}

Gravita sobre Castilla la Vieja, en primer lugar, una especie de complejo de culpa histórico que otros pueblos peninsulares se esfuerzan por agravar a costa de la conexión Castilla-centralismo opresor. En otro orden, Castilla se ha caracterizado por la imprecisión de sus fronteras, dado que, en épocas pasadas, se proyectaron hacia fuera -en el período de expansionismo histórico, que no hay por qué negar- y, ahora, se ven replegadas hacia dentro; también por hablar una lengua que, aparentemente, no sirve como fácil seña de identidad al ser empleada por tantos pueblos de distintas latitudes. Dice Delibes que es un idioma que, por extendido, ha dejado de ser nuestro ${ }^{8}$. Sin embargo, y tal como me hacia notar, hace poco, un amigo inglés, en pocas partes del mundo existe un oído tan fino para detectar las diferencias de acento entre distintas hablas. Diferencias, no sólo entre los castellanos y los demás, sino entre las singularidades de las hablas de una y otra comarca.

Desde el punto de vista territorial, ha venido ocurriendo en todos los periodos de reivindicación autonómica y nacionalista, que Castilla sea lo que resulta del reparto de los demás, lo que queda cuando los otros pueblos -o naciones- han apuntalado sus fronteras. En lo político y en lo económico, Castilla la Vieja ha sido en los últimos tiempos un área tan poco favorecida que hay autores que la consideran como periférica, por sus caracteristicas y escasa participación en el poder y en el progreso industrial, a pesar de su situación geográfica. Quienes se han ocupado de Castilla y su población suelen coincidir en caracterizarla como una región escasamente industrializada; con un campo poco modernizado pero más innovador, con todo, que la industria, y una pobreza que no se nota demasiado por haber estado tradicionalmente bien repartida. Autores como

Stanley Brandes, Metaphors of Masculinity. Sex and Status in Andalusian Folklore (University of Pennsylrania Press Publications of the American Folklore Society, 1980), p. -3

* Miguel Delubes, Castilla. lo castellano y los castellanos (Barcelona: Planeta, 1979). Dice, por ejemplo, en p. 1+2: "Pobreza, incomunicación, creciente soledad, van acentuando, dia a dia. el irreductible individualismo castellano, causa engendradora de no pocos de nuestros infortunios. 
el sociólogo Amando de Miguel, han llamado, así, a Castilla "colonia del interior o región periférica" ${ }^{9}$.

En el mapa político de las autonomías fue Castilla y León, a pesar de su reputación de zona centralizadora, una de las pocas Comunidades Autónomas que -durante años- no tuvieron una capital definida, pues la capitalidad de Valladolid era provisional. Este detalle puede sorprender, como otras muchas contradicciones semejantes, si aceptamos la imagen que se nos ha dado de Castilla desde fuera. En esa imagen ha tenido mucha importancia lo que los foráneos escribieron de Castilla, a veces con afán de ensalzarla, pero casi siempre malentendiéndola. Castilla ha sido cantada por muchos poetas y pintada por muchos pintores. La mayoría de ellos ha contribuido a trazar una imagen estereotipada: páramos, trigales y sequedad de tierras y personas. La Castilla del esplendor y la decadencia.

Lo mismo ha sucedido con sus gentes. Ni palurdos sin danzas que decía Antonio Machado, ni místicos-hidalgos que decían otros autores del 98; lo que sociológicamente asombra en la población castellana es el peso desproporcionado de clases medias no industriales que presenta. Pienso que ese fenómeno responde a la valoración, quizás desmedida, de la educación, de los "estudios"; por encima, incluso, de la mera riqueza o comodidad material. El porqué de ello debería preocuparnos más que la polémica de una Castilla dominadora o dominada. El porqué radica, probablemente, en el sistema de valores. Un sistema en que la educación, el ser "hombre de carrera", parece encontrarse por encima de los negocios y el dinero.

Está claro, además, que - según la tendencia e intereses de cada autor- pueden encontrarse en nuestra Historia razones para hablar de una Castilla democrática y lugareña, o de otra opresora e imperial; de una Castilla de siete, once o nueve provincias; de una Castilla con León, contra León -como se refleja en nuestros más antiguos poemas épicos-, o sin él. Sobre todos los nacionalismos y regionalismos se ha hecho mucha literatura, casi siempre mala, y sobre Castilla y lo castellano tanto o más que en otros casos. Y además una literatura pesimista, negativa; recordemos títulos como el de Castilla en escombros de Julio Senador ${ }^{10}$, o las palabras de otro autor castellanista, Fernández Díez: "Castilla la buena, la austera, la cenicienta, la preterida de los gobernantes, la olvidada por la indiferencia y la abulia de sus propios hijos ${ }^{11}$.

9 Amando DE MIGUel y Félix MORAL, La población castellana (Valladolid: Ámbito, 1984), pp. 11-17.

10 Julio SENADOR, Castilla en escombros (Valladolid, 1915).

11 Gregorio Fernández Díez, El valor de Castilla (Ávila: Senén Martín Díaz, 1926), p. 230. 
Esta literatura a veces la han hecho ilustres escritores, como Miguel Delibes, que nos presenta de lo castellano un cliché muy utilizado por autores castellanistas de antaño. En semejante cliché juega un papel muy importante el mito de la decadencia. Mito extensivo en el ámbito nacional a lo que tantos españoles llegaron a pensar - y piensan- de sí mismos. Mito, no porque sea por entero irreal, sino porque presupone un período de esplendor que, tal y como lo han glosado algunas mentes añorantes, no existió - en verdad- nunca. Para Delibes, el castellano - luego parece creer en un carácter nacional- es, entre otras cosas, "juicioso, sumiso, lacónico, seco, austero, fatalista, fácil presa de rencillas..., etc." ${ }^{12}$. Pretende hablar del campesino - y volvemos a encontrar a los campesinos como estereotipos de identidad- definiéndolo como ser "casi paleolítico en la segunda mitad del siglo $\mathrm{XX}^{\text {". }}$. Todo esto me recuerda una guía de Soria en la que, junto a la lista de monumentos consabida, podía leerse del soriano y su carácter que era: "pequeño, resistente y sagaz".

En realidad, los rasgos negativos que Delibes atribuye al campesino castellano serían extensibles a los campesinos de otras latitudes y países. Dice el mismo autor: "No creo que en Castilla exista una conciencia histórica y cultural profunda (...). El castellano no se siente especialmente castellano sino vaga e inconscientemente español " ${ }^{13}$. Lo que importa no es que los castellanos sean como dice Delibes que tienen que ser: lo grave sería que ellos mismos se lo llegaran a creer. Y ésa es la gran fuerza y, al tiempo, el gran peligro de los estereotipos, que en su conjunción de tradiciones - consideradas como culta y popular respectivamente- nos presentan percepciones casi siempre muy superficiales cual verdades inamovibles ${ }^{14}$.

Afirmaciones tan pesimistas como las que estoy comentando debieron influir en el hecho de que, en una publicación programática del PSOE de Castilla y León, se dijera: "Tenemos que conseguir que nuestra identidad como pueblo sea una realidad y que nuestro sistema educativo sea un elemento de apoyo, transformación y creación de nuestra región castellanoleonesa" ${ }^{15}$. Pero, en mi opinión, la cuestión no era inventar una identidad,

12 Miguel Delibes, Castilla. lo castellano y los castellanos (Barcelona: Planeta, 1979), p. 225.

13 Delibes, op. cit.. pp. 16-18.

14 Véase mi trabajo sobre "Identidad y manipulación de la cultura popular", en Aproximación antropológica a Castilla y León. Luis DíAZ (coord.) (Barcelona: Anthropos, 1988), pp. 13-27.

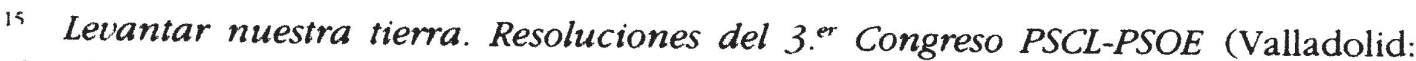
Fundación Pablo Iglesias, 1982), p. 81. 
sino conocer y relanzar la ya existente. Parece que menos aún va a hacerse ahora en este sentido, pues en labios de algún presidente de la Comunidad de Castilla y León hemos escuchado declaraciones según las cuales el modelo comarcal puede tener justificación en Cataluña, pero no en Castilla y León, pues "tradicionalmente lo importante aquí ha sido la provincia" ${ }^{16}$.

Tal referencia, vaga pero fundamental a lo etnográfico, precisa ciertas puntualizaciones: la división territorial en provincias que hoy conocemos proviene, en su trazado general, del siglo XIX y constituye, por lo tanto, una innovación que - en términos históricos- podríamos considerar reciente $^{17}$. En lo que se refiere a los castellanos, todos los estudios antropológicos de autores españoles y extranjeros señalan que lo importante en su concepción tradicional del territorio es la conciencia del pueblo y, más allá, la de comarca como ámbito cultural y comercial en el que relacionarse con los otros ${ }^{18}$. Fuera de ahí, todo lo demás parece una abstracción de políticos, burócratas y algunos intelectuales que han especulado más sobre lo que los castellanos deberían ser, que preocupado por lo que realmente son.

Esto no quiere decir que en Castilla no exista una conciencia de lo castellano; sino que su identidad es diferente, por razones históricas y culturales, a las que, por ejemplo, serían potenciadas -cuando no inventadas- en el siglo xIX por la burguesía y el clero capitalinos de otras regiones ${ }^{19}$. La identidad castellana se caracteriza por ser más cultural que

16 Esta opinión, sostenida por los principales dirigentes de la actual Junta de Castilla y León en sus discursos y declaraciones, fue expresada - en los mismos términos que reproduzco- por su $3 .^{\text {er }}$ Presidente durante una entrevista televisiva.

17 Véase, en lo que se refiere al caso de Castilla y León, la obra de Enrique ORDUÑa, El regionalismo en Castilla y León (Valladolid. Ámbito, 1986).

18 Un ejemplo de ello lo encontramos en los trabajos de Michael KenNY, A Spanish Tapestry: Town and Country in Castilla (New York: Harper \& Row, 1966), Joseph ACEVES, Social change in a Spanish Village (Cambridge and London: Schenkman, 1971), Susan TAX FREEMAN, Neigbbours. The Social Contract in a Castilian Village (Chicago: University Press, 1970) y Stanley BRANDES, Migration, Kinship and Community: Tradition and transition in a Spanish Village (New York: Academia Press, 1975).

19 La opinión de que Castilla debe de seguir sacrificándose por la unidad del Estado no es sólo una tesis de la derecha: un político de izquierdas, Manuel AzAǸA, diría a los castellanos algo muy semejante a lo sostenido por quienes siempre han visto a Castilla como "forjadora de la patria y el Imperion: "La diferencia política más notable que yo encuentro entre catalanes y castellanos está en que nosotros, los castellanos, lo vemos todo en el Estado..... Cf. Manuel AZAÑA, Memorias politicas y de guerra (Madrid: Afrodisio Aguado, 1976), II, p. 369. A este respecto véase la interpretación que, apoyándome en otros autores, doy sobre las relaciones con el Estado y quienes lo representan dentro de los pueblos castellanos, en Rito y tradición oral en Castilla (Valladolid: Ámbito, 1984), pp. 61-65. 
territorialista, y de ahí que, salvo en las capitales, apenas exista conciencia de provincia o región ${ }^{20}$.

\section{DIVERSOS NIVELES DE IDENTIDAD (CIUDAD, PROVINCIA Y REGIÓN en Castilla). el caso de Ávila}

\section{Tópicos sobre el carácter de una ciudad}

Viajeros y escritores han construido estereotipos sobre un supuesto carácter de las ciudades en base a lo específico de su apariencia física y en base, también, a un hipotético temperamento particular de las gentes que las habitan.

Respecto a la primera suposición no caben muchos reparos: es un hecho constatable que cada ciudad posee una situación y unas formas externas que le son propias. Puede haber ciudades que se parezcan - por ejemplo- sabemos que, hoy en día, muchos edificios e incluso calles y parques se repiten en serie dentro de núcleos urbanos de muy distintas latitudes. Con todo, se puede seguir afirmando que no hay en el mundo una ciudad exactamente igual a otra.

En lo que se refiere al segundo supuesto, el de que los pobladores de una ciudad tienen una "forma de ser" específica, la comprobación se hace mucho más difícil por no decir improbable. Las dudas sobre la veracidad de esta hipótesis surgen - a poco que reflexionemos- por todos los lados: hemos de creer, para que resulte cierta, que la suma de los caracteres de los individuos que viven en un lugar dado - sea cual sea su sexo, oficio, estatus, edad o verdadera procedencia- produce un carácter colectivo especial y que, además, ese supuesto carácter no sufre alteración alguna a lo largo del tiempo.

¿Qué ha sucedido entonces? Que escritores y viajeros han confundido las dos visiones, la del continente y la del contenido, la del habitáculo y la de quienes lo habitan y las han fusionado en un solo estereotipo de carácter que repiten, prácticamente, siglo tras siglo.

De Ávila se ha venido diciendo, por un montón de autores distintos, que era "mística y guerrera", con lo que se la ligaba a la idea estereotipada de lo castellano que tanta credibilidad literaria aún presenta y -más todavía - se la convertía en una especie de quintaesencia de los tópicos

- 20 Comparto la opinión de Honorio Velasco de que, entre los castellanos, "patria" es fundamentalmente el pueblo de origen y, sólo por extensión, ula nación o el Estado". Cf. Honorio Velasco, "Signos y sentidos de la identidad de los pueblos castellanos" en Aproximación antropológica, pp. 28-46. 
generales sobre Castilla. Ávila pasaba a ser, de esta manera, como una Castilla en miniatura $\mathrm{o}$, mejor, como la miniatura medieval en que a modo de laboratorio del espíritu se habría fraguado lo castellano.

Ese experimento tuvo lugar — según sus exégetas- en un clima particularmente frío durante el invierno que debió de contribuir a la "pureza" de los resultados. Vieja es también la literatura que conecta la climatología con los hipotéticos caracteres de los pueblos, de modo que el frío de Ávila cierra el triángulo de tópicos — "los tres tristes tópicos", como les denomina con cierta ironía José Jiménez Lozano ${ }^{21}$ - del espíritu colectivo abulense, si bien en el caso de este tópico sobre el clima no cabe duda de que hay una incontestable base real.

La medida en que aspectos como el del frío hayan podido influir en el supuesto carácter "prototípicamente castellano" de los abulenses es algo, ya, difícil de determinar incluso para los que, desde planteamientos pseudo-científicos, propagan la creencia —en realidad popular- de que los caracteres de los pueblos dependen sobre todo del clima o de la alimentación.

Ávila, la ciudad por fuera, su envoltura física, posee —en efectocomo tantas otras ciudades españolas (aunque a su especial manera) un horizonte henchido de torres de iglesias, conventos y palacios. ¿Garantiza esta circunstancia que en la personalidad de sus habitantes pervivan por siempre las esencias del espíritu y de la guerra? Por supuesto que no.

Quien ve aletear a esos ángeles sobre las murallas de Ávila es más bien el viajero de paso que idealiza lo que ve - cruces y escudos- trasladando esa realidad externa a un supuesto temperamento interior de toda la ciudad y de todos los que la pueblan.

\section{Las visiones literarias de Ávila}

Si bien es cierto que sobre Ávila y su hipotético carácter se han venido repitiendo, como queda dicho, los mismos pocos tópicos en una serie casi infinita de textos, no lo es menos que cada autor también ha dejado en su imagen de la ciudad algo de su experiencia personal respecto a ella.

Así, José Luis L. Araguren y José Jiménez Lozano - por citar a dos de los escritores que más recientemente y con mayor penetración se han ocupado del tema- pueden hablar, el uno, de una Ávila "ciudad lejana", "demasiado mural" y "demasiado histórica", o de una Ávila más "esencial", más vista desde dentro, el otro: esa Ávila, "la casa", que ya había intuido Unamuno.

21 José Jiménez LozAnO, Ávila (Barcelona: Ediciones Destino, 1988), pp. 13-17. 
Todo depende, de hecho, de la perspectiva desde la que veamos o, mejor, nos acostumbraremos a ver - las cosas. Y las dos visiones la visión en la distancia y la visión próxima y familiar- son etnográficamente ciertas y hasta complementarias.

Entre una y otra visión caben un buen número de aproximaciones intermedias que podemos encontrar en los textos de sus visitantes más o menos ilustres. Lo que sucede es que, a veces, esas visiones más que distintas resultan frontalmente contradictorias. $Y$ es entonces cuando hay que preguntarse cuál es la que menos yerra, más allá de las variabilidades de la historia o de los deseos que cada observador tiene de acomodar lo que ve a lo que quiere encontrar.

Así, Dionisio Ridruejo coincide, por un lado, con otros tantos viajeros en los tópicos ya mencionados y habla de la "singularidad amurallada" de Ávila y define a la ciudad (monjes y soldados de nuevo) como la simbiosis de un convento en un castillo". Pero, de otra parte, descubre en ella "una pureza castellana nórdica y europea" 22 que choca con la idea de esa Ávila orientalizante - entre Oriente y Occidente, al menos- que Aranguren y Jiménez Lozano rastrean (en esta ocasión al unísono) en las huellas de sus juderías, barrios de moriscos y palacios, y casas abandonadas por los no cristianos.

A este respecto, la historia -más que la realidad de la Ávila actual en que unos y otros rasgos son, sobre todo, piedras y ecos- parece dar la razón a los segundos, sin quitársela del todo a Ridruejo, pues en su cascarón la ciudad sí puede tener aún el aire de una miniatura medieval europea, francesa o alemana.

Ridruejo abunda, también, en aquellos tópicos sobre los cuales todos los glosadores de Ávila dan la impresión de estar de acuerdo, si bien señala, con sagacidad, la posible superficialidad o esquematismo que tienden a identificar a Castilla con una idea igualmente estereotipada de lo castellano: "Aunque quizá sea espejismo, se ve físicamente aquí esa dualidad monástico-guerrera que el tópico atribuye a Castilla quedándose en su esqueleto o en su caparazón y despreciando su carne perecedera y jugosa" ${ }^{23}$.

O como escribía Antonio Veredas, haciendo una síntesis gloriosa - no en vano su libro Cuadros abulenses se publicó en 1939, "año de la victoriande los principales tópicos sobre Castilla y Ávila:

22 Dionisio Ridruejo, Castilla la Vieja. Soria-Segovia-Ávila (Barcelona: Ediciones Destino, 1974), p. 143. Las opiniones a las que me refiero, como contrapartida a este parecer de RIDRUEJO, son la de J. JimÉnEZ LOZANO, contenida en el libro arriba citado, y la de José Luis ARANGUREN en Ávila de Santa Teresa de Jesús y de San Juan de la Cruz (Barcelona: Editorial Planeta, 1993).

23 D. RIDRUEJO, op. cit., pp. 441-442. 
El corazón de España está adornado con una joya de oro que se llama Castilla, joya de oro en la cual deslumbra un brillante que se llama Ávila de los Caballeros [...] Yo te ruego, lector, emplees intensamente tus energías en hablar al mundo de estos reflejos, para honra del brillante que los produjo y para la gloria de la alhaja de oro que contiene el brillante y que adorna el corazón de España ${ }^{24}$.

Hubo quienes en la década de los 40 irían todavía más lejos. Soplaban "Vientos de imperio", a imitación del "modelo italiano" que se desmoronaría tan lastimosamente durante la Segunda Guerra, y decía Martín Alonso en su Libro de buen andar:

Castilla mira a España a través de su paisaje con los ojos de un asceta y de un guerrero. La naturaleza confina a nuestros deseos las hazas bronceadas de sol y heladas por la escarcha, los campos de suaves labranzas dilatados en la austeridad y las torres de pesada arquitectura medieval, que se yerguen en los llanos como la armadura de un cruzado ${ }^{25}$.

Lo cierto es que esa creencia en el "temperamento" batallador y devoto de las gentes de Ávila —y de Ávila misma - viene de muy antiguo, pues Gil González Dávila citaba, ya en el siglo xvil, muy remotas fuentes para justificar -incluso con argumentos astrológicos- el pretendido carácter de su lugar natal: "Ávila, según Ptolomeo, está apartada quarenta y un grados de la Equinoccial, sujeta al signo de Virgo, y a Marte: destos Planetas el primero haze a sus moradores templados, prudentes, afables y religiosos, como se manifiesta en su trato, y composición de vida. El segundo los inclina a honor, y fama de las armas, con ánimos invencibles" ${ }^{26}$.

En la misma época en que González Dávila escribe esto, el desconocido autor del Quijote conocido como "de Avellaneda" por el pseudónimo que aquél utilizó, hace decir a uno de sus personajes (en el capítulo XIV) razones muy parecidas a propósito del carácter abulense, lo que confirma que el tópico del que hablamos se hallaba ampliamente difundido en nuestros siglos dorados y que no era sólo especulación aislada de un escritor erudito.

Se lee, así, en este Quijote apócrifo: "Yo soy, señor mío, de la ciudad de Ávila, conocida y famosa en España por los graves sujetos con que la

24 Antonio VEREDAS, Cuadros abulenses. Observados con los ojos del alma (Ávila, 1939), pp. 7-8.

25 Martín ALONSO, Libro de buen andar. Prosas castellanas de romería (Madrid: Editora Nacional, 1942), p. 10.

26 Texto de Gil GonZález Dávila incluido en la muy completa obra de Benito HERNÁNDEZ ALEGRE, Ávila en la literatura II. Narrativa-teatro-viajes (Ávila, 1984), p. 19. 
ha honrado y honra en letras, virtud, nobleza y armas, pues en todo ha tenido ilustres hijos" ${ }^{27}$.

No era disparate sin duda este encuentro entre un abulense de familia de caballeros, como los Bracamonte, y el singular caballero "de la triste figuran. Siglos después, Gregorio Marañón hará una nueva síntesis de este estereotipo tan dilatado en el espacio y el tiempo acerca de Ávila.

El popular "santos y cantos", que ya venía - de tiempo atrás- definiendo a la ciudad, va a convertirse, con leve variante, en "Ávila, caballería y misticismo". Y el autor aclarará lo que ello, a su parecer, significa:

Porque no hay caballería verdadera sin un sentido de puro ideal místico. Las piedras apasionadas e inmortales de Ávila y el paisaje que circunda la ciudad nos enseñan que el ser caballero no consiste en tener ilustre la prosapia, ni la hacienda pingüe, ni aderezos pomposos, ni maneras corteses, sino que el alma esté, en cada instante de la vida, dispuesta a la renunciación propia de la conveniencia, para servir a lo que conviene a los demás. Esto, que es la pasión de la caballería andante y el alma de la caballería verdadera, ¿qué otra cosa es el misticismo ${ }^{28}$.

Finalmente, Marañón identifica el "alma" de Ávila con el de Castilla toda, si bien estableciendo algunas curiosas diferencias entre otras ciudades de las dos Castillas - no parece que hable de las provincias en este caso- y la ciudad amurallada:

Ávila no recrea y descansa, como León; no enseña la vieja sabiduría como Salamanca; no fortifica, como Segovia; no enardece, como Burgos; no hace soñar como Toledo, sino que nos sumerge en ese lago pulcro donde el firmamento se refleja, que es la caballería y el misticismo. Esta sensación de caballería andante de lo sobrehumano, de generosidad, que no aspira a ser correspondida, nos acompaña en cada rincón, en cada plaza señorial, en las iglesias como en los palacios abulenses. Y, en verdad, es esto y no otra cosa el alma de Castilla. La pura esencia de Castilla hay que localizarla en la generosidad ${ }^{29}$.

El cretense Nikos Kazantzakis también va a descubrir en Ávila, sobre los años 30, esa misma dualidad del alma castellana que, yendo más lejos -quizá porque venía de otras tierras-, identificará con el carácter español: "Alta, desértica, así parece Castilla la Vieja, esta forja donde fue formada el alma española" ${ }^{30}$.

27 En B. HeRnández Alegre, op. cit., pp. 14-15.

28 Textos de Gregorio Marañón seleccionados por B. HERnÁNDEZ AlEgre, op. cit., pp. 108-109.

29 Ibid., p. 109.

30 Fragmentos de Nikos KAZANTZAKIs extraídos de su España-Cuadernos de viajes. 1926 octubre-noviembre 1936 que recoge B. HERNÁNDEZ ALEGRE, op. cit., p. 274. 
Y hablará de conceptos muy semejantes a los que utilizara Marañón para definir la esencia de Castilla y de España, si bien desnudándolos de su trascendencia religiosa al enfrentarse con el espíritu de lo español en su dimensión puramente humana:

He aquí cómo podría explicarse la aparente contradicción del alma española que la lógica no ha permitido conocer a tantos sabios: pasión y nada. Éstos son los dos polos alrededor de los cuales gravita. La pasión, la sed, el cálido abrazo de la vida, y al mismo tiempo la sensación de que todo esto no es más que nada y que la muerte es nuestra Gran Heredera. Pero cuanto más un alma fuerte siente esta nada, más intensamente vive cada uno de sus vanos y efímeros minutos. Para las almas fuertes, la muerte es siempre el más poderoso excitante ${ }^{31}$.

Aunque Kazantzakis no proporciona argumentos en que apoyar estas audaces especulaciones no resultaría difícil encontrarlos en el comportamiento de los españoles a lo largo de la historia y, especialmente, en el período barroco que, con probabilidad, sea el que este autor tiene más presente al escribir tales palabras.

La observación de Kazantzakis se desmarca de aproximaciones bellamente literarias - pero interesadas y pensadas "desde dentro" de la propia sociedad sobre la que se escribe, como las de Marañón y tantos otros. Esto quizá le permite, a diferencia de aquéllos, superar - en cierto modo- el tópico y situarnos frente a lo que (al menos en determinadas épocas históricas) sí ha podido parecerse a la visión que los españoles tenían del mundo. Cómo lo entendían de acuerdo con un sistema de valores que les colocaba en una situación de orgulloso desdén —sólo aparente- hacia la vida y la muerte.

Pasión y nada: una actitud exasperada ante la vida y casi complacida - por plena consciencia, que no por resignación - ante la muerte. Esto sí que puede interesarnos ya más, antropológicamente, pues por encima de la creencia en un alma colectiva -que como hemos visto Kazantzakis sigue conectando entre niveles cada vez más amplios de identidad (ÁvilaCastilla-España) - el autor adivina visiones del cosmos y sistemas de comportamiento en las acciones más espectaculares de unas gentes concretas.

Quizá las claves de la cultura entendida como española - por supuesto que habría que hacer distinciones de matiz también entre las diversas culturas que la conforman- estén más en ese apasionado escepticismo (pasión y nada) que en todos los demás tópicos, autocomplacientes y mojigatos, que hemos ido desglosando. Pasión y nada que les ha llevado a interpretar

31 Ibid., p. 274. 
el mundo - durante amplios períodos de la historia - de forma absoluta, extremada: como una tensión entre principios opuestos que sólo se fusionaban en la muerte o - más aún- en el perdón divino. Habría también que aclarar cuáles son las versiones que las vertientes popular y culta - dentro del conjunto de nuestra cultura- dan de este problema según las distintas épocas, pues esa conjunción de tradiciones resulta particularmente importante en la creación de los estereotipos de la identidad.

Tal contradicción de tópicos, en todo caso, tiene bastante que ver con el fondo conceptual de una novela situada en Ávila - muchos pensaron que expresión cabal de la ciudad, aunque a mí siempre me hizo pensar más en la Toledo imperial- como es el caprichoso y atrevido relato de La gloria de Don Ramiro, de Enrique Larreta. Unamuno alabó con gran entusiasmo, en su momento, esta novela que, hoy, se nos antoja demasiado artificiosa y que escritores como José Jiménez Lozano han criticado no sin razón ${ }^{32}$.

El mayor acierto, quizá, del libro de Larreta — consideraciones estilísticas aparte- sea mostrar esa dualidad, esa cadena de contraposiciones, el sublime contraste que (sobre todo a los ojos de quien viene de fuera) parece haber marcado gran parte de la vida y cultura españolas durante largo tiempo.

En este sentido - y a pesar de sus muchos excesos - la novela de Larreta apunta hacia una visión más auténtica de lo español (genéricamente entendido) que un buen número de las glosas de viajeros vertidas sobre Ávila y Castilla. Gran parte de estos comentarios caen, con frecuencia, de un solo lado en su visión de la realidad. Así se han ido construyendo, literariamente - pero, a menudo, en combinación también con estereotipos de carácter más popular- una serie de tópicos en torno a Ávila que nos la presentan tan pronto de una forma como de la forma contraria.

Algunos de esos tópicos —en franca contradicción interna- los hemos repasado ya: Ávila la recogida, la aislada, y sin embargo epicentro del eje espiritual de España y aun de Europa, para los más osados; Ávila nórdica o Ávila oriental; Ávila la ciudad lejana o Ávila la casa; Ávila ciudad y aldea a un tiempo, rus in urbe y más exactamente Oppidum in agris como señalaría uno de sus más agudos conocedores, Jorge Santayana ${ }^{33}$; Ávila local o cosmopolita, siempre viva o mundo fosilizado, tal y como la definiera Agustín Galvet, "Gaziel" ${ }^{34}$.

32 J. JimÉNEZ LOZANO, op. cit., pp. 80-81.

33 Texto de Jorge Santayana transcrito por B. Hernández Alegre, op. cit., p. 99.

34 Idea expuesta en un texto titulado "Castilla de los héroes y los santos" de Agustín Galvet, "Gaziel", que recoge B. HERNÁNDEZ AlEGRE, op. cit., pp. 249-254. 
Y Ávila entre lo austero y lo sensual, entre la humildad y el orgullo, entre la mezquindad y lo sublime, entre el horror y el arrepentimiento, que así precisamente vio Larreta a su Ávila y a su Ramiro. Eso sí, puede que sintetizando groseramente - pero como tantos otros, por otra parteunas ideas bastante abstractas de Ávila, de Castilla y de España.

Larreta, además, transporta la observación directa de la Ávila que él pudo conocer a la más remota que Ramiro habitaba y -en ocasioneslas conjuga en una agria pintura de esa pequeña ciudad ensimismada. Es, aquí, de mezquindad y no de grandeza de lo que se nos habla; del tedio de unas gentes encerradas en sus convencionalismos y no de las proezas de héroes o de santos:

El cuadro invariable que había contemplado tantas veces desde la infancia se manifestaba ahora con otro sentido. La taciturna ciudad dentro del cerco almenado que suprimía todo horizonte; la adusta soberbia de los caserones, evocando nombres tantas veces pronunciados, con todo el entretejo de odios, envidias, de imposturas; el andar rutinero y villano de la existencia comunal que cada minucia recordaba, y, en fin, tanta sordidez, tanta monotonía, saltáronle a los ojos haciéndole considerar la estrechura de cárcel que había bastado a su ardimiento ${ }^{35}$.

Del texto de Larreta se desprende que una misma ciudad puede verse de una manera o de la opuesta según los ojos de quien mira si nos quedamos en lo superficial. Lo que no quiere decir que no exista una dependencia interna entre sus pobladores y su realidad física; un vínculo íntimo que, desde luego, va bastante más allá de las elucubraciones líricas que el bello paisaje de piedras inspira al viajero.

La postal no son los habitantes $\mathrm{y}$, menos, su supuesto "carácter"; pero no cabe duda de que entre lo que son las ciudades por fuera y la visión del mundo u organización social de sus habitantes tiene que haber un condicionamiento mutuo al cabo de los siglos. Como ocurría con el personaje de Larreta, una ciudad - en cuanto a panorama paisajísticopuede despertar unos sentimientos de acuerdo con el estado de ánimo de quien la está contemplando.

Al margen de estas sensaciones encontradas - producto del subjetivismo- una ciudad nos ofrece datos, en su corporeidad, que sugieren claves más objetivas de entendimiento. Ávila, una ciudad amurallada que no crece porque sus habitantes no han querido o no han podido hacer que creciera. Muchas ciudades españolas tuvieron $-\mathrm{y}$ aún tienen, muchas veces derruida - su muralla. ¿Por qué Ávila sí ha conservado la suya? Algunos avatares históricos habrán incidido seguramente en ello, pero

35 Enrique R. LARreta, La gloria de Don Ramiro (Madrid, 1908). 
- aparte de estas circunstancias - podemos suponer que quienes viven en ella han tenido poderosas razones para que así fuera.

Ese es el problema que ha de interesarnos; una pregunta a la que viajeros y escritores casi siempre respondieron a la inversa: dando por hecho que la ciudad y sus pobladores tenían un "carácter" que les venía de su muralla. Y algo podría haber de esto, en cuanto que - como queda dichouna realidad física dada condiciona, probablemente, ciertas cosas. Pero, sobre todo, lo que importa es por qué sus habitantes han mantenido la muralla intacta.

Todos sabemos, por los ejemplos abundantísimos de otras urbes de la Península, lo fácil que resulta - por motivos militares o especulativosque una muralla desaparezca. ¿Por qué la de Ávila no debía ni podía desaparecer?

Ávila, vista por distintos ojos, ha sido reinventada como símbolo de lo localista o de lo universal, como la Castilla más pura y no contaminada o como punto de encuentro entre Oriente y Occidente. No andaba, quizá, tan desencaminado Larreta - a pesar de sus delirios modernistas- en imaginarla como una Jerusalén castellana; ni Jiménez Lozano, más tarde, al suponérsela (ya desde su infancia) como una especie de Constantinopla mesetaria. Una y otra comparación puede que hayan tenido su sentido para determinadas etapas de la historia de la ciudad. Comparar, hoy, una y otra urbe revela, sin embargo, que Jiménez Lozano debe de conocer bastante bien Ávila - lo que demuestra, para algunos aspectos, en su libro sobre ella- pero posee una idea bastante inexacta de lo que actualmente es Constantinopla.

¿Ávila o el "capricho bizantino" varado en ese Libro de Horas que podría ser Castilla? Quizá. Pero, sobre todo, y ahora mismo, una ciudad y unas gentes que eligieron seguir tras su muralla. Ávila, segura y prisionera en sus propios tópicos.

\section{Ciudad, provincia y región}

El prestigio literario e histórico de Ávila, la ciudad, ha venido ensombreciendo un tanto el conocimiento de su provincia, no menos interesante y verdaderamente variada. Por otro lado $-\mathrm{y}$ como hemos visto- se ha tendido a conectar a la ciudad con su dimensión regional e, incluso, nacional, en cuanto a paradigma o símbolo de un antiguo espíritu castellano y español.

De ahí que algunos de los libros que prometen ocuparse de sus otras tierras se queden en la consabida glosa del carácter castellano y en unas 
mínimas alusiones al pintoresquismo de los aldeanos que uno puede ver transitando por la urbe.

Este es el caso de una obrita de León Roch quien, en tiempos del reinado de Alfonso XIII, recoge la siguiente impresión abulense:

Encontraréis gentes hidalgas y buenas, prudentes y reflexivas; digna representación del austero pueblo castellano, émulas en virtud, en piedad y en nobleza de sus antepasados. En sus calles se ven con frecuencia las extrañas y simpáticas figuras de los campesinos de ceñido calzón y de las mujerucas de refajos de colorines, que son un encanto para el turista extranjero y para los fotógrafos de afición. Estos campesinos, casi todos vestidos de negro, con anchos sombreros y fuertes fajas de estambre o de cuero, de graves rostros, que no contraen el rictus de la más leve sonrisa, parecen hombres de una raza especial. En ellos se revela todo el carácter de la austera y fuerte raza castellana ${ }^{36}$.

Jiménez Lozano, ya en nuestros días, habla en tonos mucho más realistas de estos personajes del campo y hace notar la diferencia -común a tantos otros lugares - entre las gentes de la montaña y del llano. Dice, así, este escritor:

Todo el mundo parecía consciente de que las gentes de Ávila pertenecían a dos grupos humanos distintos: los de la sierra y los de la llanura o Moraña. Gentes de rostro colorado, las primeras; muy morenas o muy pálidas, las segundas. Un habla de entonaciones cantarinas y finales abruptos el de aquéllas; un habla más uniforme y monótona, lenta y circular, el de éstas. Gentes de hortaliza y cordero, los serranos; gentes de jamón y torrezno los morañegos. Perduración de una manera de vestir antigua entre aquéllos, que era mucho menos frecuente entre éstos, de modo que la eventual utilización en la Moraña de refajos y pañuelos o faldas de color en las mujeres y de alforja entre los hombres - alforjas de espléndidas listas azules y rojas o dibujos geométricos tan orientales- se tenía por "cosas de serranos". Y un habitante de la capital distinguía inmediatamente a cada miembro de esos grandes grupos, incluso si iba endomingado y con su traje burgués de ir a Ávila ${ }^{37}$.

También comenta Jiménez Lozano cómo los abulenses de la sierra Sur y Este de Ávila eran considerados como toledanos, cacereños o, incluso, madrileños, teniéndose a sí mismos los de la llanura — más hidalgos y señoritos- por los verdaderos "Castellanos". Y ciertamente, en cuanto se mira a algunas de las zonas de la provincia, hay que tener en cuenta los viejos lazos de interinfluencia que siempre relacionaron a los de la serranía con Extremadura - la trashumancia de los ganados sigue practicándose en determinadas zonas- o con Madrid.

36 León Roch, Por tierras de Ávila (Madrid, s.a.), pp. 39-40.

37 J. JiMÉNEZ LOZANO, op. cit., pp. 51-52. 
Los habitantes de ciertas aldeas de Gredos enfocan más su vida hacia Plasencia que hacia Ávila capital, como bien nos ha mostrado alguna monografía antropológica reciente ${ }^{38}$. Y es que mientras Plasencia representa algo así como un paraíso urbano para ellos, centro de compras y diversión, Ávila se corresponde con el lugar al que sólo acuden para solucionar problemas administrativos o para hospitalizarse.

De otro lado, la influencia de Madrid ha provocado una auténtica avalancha de turismo temporero que ocasiona la transformación de las artesanías tradicionales y la alteración de las formas de vida ${ }^{39}$. En Ávila, como en tantas otras zonas de la Península, también los pueblos han tendido a homologarse con el modelo urbano, siendo este proceso de "urbanización" un importante factor de cambio, tanto en la apariencia física de los núcleos rurales como en las costumbres de sus habitantes.

Alberto Klem, en su, ya, clásico trabajo sobre La cultura popular de Ávila señala las diferencias entre

la altiplanicie castellana -comprendido el Valle de Amblés- y la sierra y, en la misma, entre la ladera septentrional y meridional. Estas tres zonas - prosigue el autor - se distinguen netamente en todos sus aspectos: en la forma de las poblaciones, en la construcción de las casas, en los cultivos y en la indumentaria: hasta los hombres son distintos ${ }^{40}$.

Para Klem, que también reseña las concordancias entre estas tres grandes zonas de Ávila y otras áreas vecinas, "las congruencias anotadas demuestran que condiciones de vida similares pueden determinar aspectos de la cultura popular semejantes y hasta coincidentes" ${ }^{41}$. Conclusión nada original en antropología - aunque algunos quieran presentárnosla como novedosa ahora- y no exenta de discusión pues, como sabemos, con frecuencia esta supuesta ley ofrece curiosas excepciones.

Lo que sí queda claro en la obra de Klem es el carácter específico de cada una de las grandes zonas de Ávila e, incluso, la cultura particular de algunos de sus lugares, de modo que la realidad de Ávila, la provincia, trasciende en mucho el cliché y estereotipos que —como vimos- aún circulan sobre Ávila entendida sólo como ciudad.

38 La obra a la que me refiero es la tesis doctoral de William KAVANAGH sobre un pueblo serrano de Ávila, parcialmente publicada como Villagers of the Sierra de Gredos (Oxford: Berg, 1994).

39 Cif., en Guía de la artesanía en Castilla y León. Ávila (Valladolid: Junta de Castilla y León, 1991), p. 17.

40 Albert KLemm, "La cultura popular de la provincia de Ávila", en Anales del Instituto de Lingüistica, T. VIII (Mendoza, 1962), p. 5.

41 Ibid., p. 225. 
Ese descuido en torno a este territorio de la España central y a sus pobladores ya fue apuntado, certeramente, por Julio Caro Baroja: «Los poetas más grandes han cantado la inmensidad de su campo o el carácter de sus ciudades. Del pueblo perdido en la sierra o en la antiplanicie no se ha hablado demasiado en cambio" ${ }^{42}$.

Ávila, como Castilla con la que tanto se la relaciona, la cantada mil veces y la mil veces reinventada. Pero Ávila, también, la desconocida.

III. IDENTIDAD Y CONMEMORACIONES: APUNTES SOBRE LA FIESTA DE VILLALAR y la CElebración del Día de la COMUnidad en CaStilla y león

\section{Impresiones sobre una romería más bien laica}

Durante los días siguientes a la celebración del día de la Comunidad en Castilla y León la palabra identidad ha aparecido con frecuencia en los medios de comunicación, en labios de personajes muy diferentes. Ya he explicado en más de una ocasión que decir - y nuestros políticos siguen haciéndolo- que los castellanos y leoneses no tienen conciencia de identidad es, antropológicamente, una tontería.

Otro asunto, que suena parecido pero resulta en realidad muy diferente, es reconocer que apenas existe conciencia de identidad regional en Castilla y León. Que mucha gente, empezando por la mayoría de nuestros dirigentes hasta hace muy poco, no se creían o toleraban con reticencias el hecho de la identidad regional. A pesar de las diez mil personas reunidas recientemente en Villalar y del ataque "nacionalista" que aqueja a algunos integrantes del $\mathrm{PP}$, semejante panorama no ha cambiado en demasía durante los últimos años. Y ello, por otro lado, no habría de sorprender a nadie cuando la "regionalidad" castellano-leonesa constituye una novísima manera de identificarse y organizarse administrativamente. Pero una cosa es que las gentes no se identifiquen con lo regional y cosa muy distinta es suponer que no saben lo que son, ni quiénes son: que no tienen identidad alguna.

Claro que imaginarse este disparate puede resultar bastante cómodo para cierto discurso político que justifica sus deficiencias en base al centralismo del gobierno del PSOE y a la supuesta falta de identidad de castellanos y leoneses: aquí no se puede hacer más - parecen decir algunos líderes de la región- porque Madrid no concede más competencias y porque la gente no cree en su propia identidad. El primer argumento es un viejísimo caballo de batalla de todos los nacionalismos, pero el segundo constituye en sí una falacia de lo más extravagante.

42 Cif., en Klemm, op. cit., p. 226. 
¿No será, también, culpa de quienes gobiernan y gobernaron el no haber acertado a convertir en proyecto creible ese armazón - si no armatoste- casi únicamente burocrático de la administración regional? Nuestros políticos, ya sean los más altos cargos del gobierno o los más modestos dirigentes de las autonomías, se están acostumbrando peligrosamente a echar la culpa de los fallos al "pueblo" del que - hasta hace poco- hablaban con tanto entusiasmo, o a las imposiciones de una estructura que se halla por encima de ellos: Europa, los misterios y exigencias del capitalismo internacional, las leyes del progreso, el anciano "coco" del centralismo matritense...

Mientras tanto, la administración a menudo se duplica en complejidad e ineficacia o, incluso, llega a triplicarse en esa práctica tan extendida de encargar a empresas privadas labores que las propias administraciones deberían ser capaces de desempeñar.

No he sido yo el primero en señalar el carácter de "romería" que la fiesta de Villalar - en principio una reivindicación descentralizadora de unos pocos izquierdistas castellanos - ha ido tomando en los últimos años. Ahora, después de la reciente y postrera convocatoria villalarina, la cosa parece más clara todavía: muchos de los que estuvieron presentes en la campa - trabajadores de Santa Bárbara y NICAS, por ejemplo- fueron a manifestarse contra la apurada situación en que se encuentran, lo que es también una manera de rogar a los santos-mártires de la guerra de las comunidades para que velen por ellos ante esa amenaza de un porvenir tan incierto. La división de celebraciones de la que los cronistas se han hecho eco en estos días, con lamentos a veces algo ingenuos, no es nada casual; por el contrario, viene a plasmar alegóricamente dos maneras muy distintas de entender la identidad y la autonomía. La "celebración unitaria" no será, probablemente, posible hasta que no se produzca la conjunción real de esos dos diferentes modelos de región.

Gloria, pues, a los comuneros en las alturas, pero - mientras- en la tierra los oficiantes de la "regionalidad" de Castilla y León no parece que quieran tener que ver mucho o nada con ellos. Todo culto $-\mathrm{y}$ el de la identidad lo es- precisa santos, héroes o mártires (y si las tres cosas se dan juntas, mejor), más una época y un lugar fijos: ese santuario donde llevar a cabo la acción repetitiva que los rituales exigen, para -asíponer al día los sentimientos y esperanzas de siempre dentro del mismo marco tradicional. La solución estratégica de organizar una celebración itinerante contradice en sí misma los fines que se pretenden, ya que su efecto es - por esencia- disgregador; no aglutina identidades, sino que las atomiza y revuelve sin llegar nunca a fundirlas.

Hoy, seguramente el modelo "comunero" que se reivindicaba en los primeros Villalares para muy poco, ya, nos podría servir en cuanto a 
región: era vago, impreciso - pues nadie sabe muy bien en qué consistía-, históricamente inexacto y, en lo político, tan arcaico como inviable. Pero también hemos de preguntarnos por la utilidad y sentido de los modelos que desde entonces se han venido sucediendo en Castilla y León, y que se aproximan más al diseño de una "super-diputación" que al de una Comunidad Autónoma.

\section{La triste conmemoración de una derrota o la búsqueda de una identidad nunca encontrada}

La celebración del "día de Villalar" nació, recientemente, como un ritual de la identidad castellana que pretendía reunir en aquellos parajes desolados a quienes creían en un resurgir de esta comunidad. Este ritual, un tanto desestructurado $\longrightarrow$ sin estructurar todavía, a pesar de los años transcurridos- se ha venido caracterizando por la pluralidad de acciones e intenciones dentro del mismo recinto y por las muchas paradojas que en torno a él se producen.

Hoy, por ejemplo, el día de la comunidad se celebra en Villalar y uen el sitio que toque" cada año, perpetuándose por el gobierno regional aquella modalidad de celebración que José $M{ }^{a}{ }^{a}$ Aznar inaugurara durante su mandato. Pocos dudarán, ya, que lo que el líder del PP pretendía con aquella instauración de unos "juegos florales itinerantes" era vaciar de contenido el ritual de Villalar: al desubicarlo, el día en cuestión perdería el valor simbólico que hasta entonces había tenido.

Sin embargo, no es esto - exactamente- lo que ahora ocurre: el ritual de Villalar, que ha conocido tiempos en que fue "sacralizado" por el gobierno autónomo cuando éste estaba en manos del PSOE, fue luego abandonado a su suerte con la intención - mal disimulada por Aznar y los suyos- de dinamitar su significado y proyección; pero algunas gentes siguieron acudiendo como quien va en peregrinación a un lugar para dar testimonio de su creencia. En total desorganización, casi con recogimiento, muchos acudían allí — aunque el día "oficialmente" se celebrara en otra parte- como quien realiza un acto de fe personal.

Por eso, quizá, Villalar en los últimos años más que una fiesta parecía un "via crucis", o una romería de vencidos que coincidían con sus derrotados ancestros en una fecha y un ámbito de desolación. Y en Villalar más paradojas - vagabundeaban juntos por unos momentos los que semejaban orar en silencio por el futuro de su tierra y de ellos mismos, y los que sistemáticamente iban "a armar ruido" año tras año.

Villalar, hoy -algo a la fuerza- día de "Castilla y León" pero en 
principio sólo día de la "castellanidad", es una fiesta que se celebra en otro lugar, una manifestación de identidad en la que los participantes no pueden ocultar su desunión, y un clavo ardiendo en la mano de quienes gobiernan esta autonomía. Tan desorientados como los celebrantes de este gran ritual de la contradicción, no saben si volver a Villalar u olvidarlo para siempre, y regresan — casi secretamente- cuando no hay peligro de encontrarse con los verdaderos fieles del extraño culto.

\author{
Luis Díaz G. Viana \\ Departamento de Antropología \\ Instituto de Filología \\ CSIC, Madrid
}

Este trabajo trata de la construcción legendaria de la identidad en un caso específico: el de los orígenes y carácter de Castilla la Vieja. El artículo también pone especial énfasis en la doble influencia - de la "gran" y "pequeña" tradición- en la creación de los estereotipos regionales y nacionales. Tal aproximación a la identidad se centra en los diferentes niveles de identificación que los castellanos acostumbran a emplear según el contexto, lugar y tiempo.

This paper deals with the legendary construction of identity in a specific case: the origins and character of Old Castile. The article also enphasizes the double influence of the "great" and "little" traditions in the creation of regional and national stereotypes. This approach to identity focuses on the different levels of identification that castilians have used depending on context, place and time. 